\title{
THE UNSPEAKABLE: TRAUMA AFFECTED NARRATIVES
}

\author{
Lorinda Tang | Deakin University
}

\begin{abstract}
This paper explores questions for writers who are depicting traumatised characters in their creative practice. As a literary trope, 'the unspeakable' has been relied on as a shorthand for traumatic experience and the ongoing affects of trauma. This paper asks whether the unspeakable is adequate to convey the lived experience of trauma, or does it minimise or sideline trauma? Does recourse to the notion of the unspeakable prevent misappropriation of stories or does it lead instead to other kinds of misrepresentation and marginalisation? How can writers, appreciating the complexities raised by the notion of unspeakability, still convey truth and inspire empathic readings when speaking about trauma?

The unspeakable prevails as a preoccupation in literary trauma theory. This paper argues that understanding the affects of trauma in the context of the unspeakable may inform a more nuanced and ethical writing practice, while also considering whether writing about trauma requires the kind of evolution of speech demonstrate by Marguerite Duras in her novels The Lover and The North China Lover.
\end{abstract}

BIOGRAPHICAL NOTE

Lorinda Tang is an Adelaide based writer of fiction and short stories. She has an extensive background in professional and legal writing. 
Before focusing on her writing career, Lorinda worked as a nurse and a lawyer. This experience underpins her concern with the ethics of creative writing, and the way in which intimate life events are explored. Lorinda is currently pursuing a $\mathrm{PhD}$ through Deakin University.

KEYWORDS

Trauma-affect-Unspeakable-Duras

This paper arises from the synchronicity of reading literary trauma theory and affect theory in the shared time-space of the Royal Commission into Institutional Responses to Child Sex Abuse, \#metoo, and the George Pell trial and appeals. As a survivor of trauma, and a writer depicting traumatised characters, it seems timely to consider the 'unspeakable' in creative practice. The unspeakable conundrum operates on two levels: for survivors, it is the 'conflict between the will to deny horrible events and the will to proclaim them aloud' (Herman 1992: 1); for writers, it is 'the explicit admission of the inadequacy of language ... [that] points to the overwhelming, soul-destroying quality of [an] experience' and lowers the audience's expectations of narrative structure and form (Stampfl 2014: 15, 21).

According to the American Psychiatric Association, trauma has been defined as the experience of 'actual or threatened death, serious injury, or sexual violence' (2013: 271). In this definition, it may be experienced directly, indirectly (through knowing family or close friends have experienced trauma), or vicariously. Trauma is not determined or measured by an event. Rather, trauma relates to an individual's experience of an event, and any post-traumatic symptoms consequently experienced (American Psychiatric Association 2013: 271).

For some, having their experience diagnosed or defined as trauma can be itself a traumatic event, as it may seem to generalise their experience and/or make it 
reductive. Trauma survivors can tend to share patterns of symptoms, and traumatic events follow certain trends, but no experience of trauma is ever the same as another, because no one can ever occupy the same chronotope-the time-space of the self's existence, within which it perceives, thinks and acts, and which is relative to every other entity (Bakhtin 1981: 84; Holquist 2002: 20, 21, 33) - as the person who lives the trauma, and there can never be a duplication of all the surrounding contexts (personality, socialisation, culture, etc). Trauma is an utterly unique and isolating experience.

My particular interest is interpersonal trauma. I use 'interpersonal trauma' to describe harm caused within significant relationships. Domestic violence, sexual abuse and/or assault, and institutional bullying predominate this kind of trauma. Interpersonal trauma is often literally unspeakable, because of posttraumatic symptoms (such as post-traumatic stress disorder), and/or because victims are disempowered, younger, less educated or otherwise marginalised, and because a characteristic of having experienced interpersonal trauma is the loss of agency. The unspeakable in narrative can be literal, when the writer is a traumatised person, but it may also be ethical (for example, to avoid harm or misappropriation), or strategic, if used as a narrative device.

\section{The Lover and The North China Lover}

In this paper, I use literary trauma theory and affect theory to explore two tellings of the same story by Marguerite Duras: The Lover (1984) and The North China Lover (1992). Before writing these novels, Duras wrote The Sea Wall, which depicts her childhood and details her family dysfunction. I do not examine that novel here as its scope exceeds the specific time frame that is the focus of The Lover and The North China Lover. However, the subject matter of Duras's family trauma is a significant influence in the narratives she writes, and the ways in which she writes them.

In The Lover and The North China Lover, the events occur in French Indochina (now Vietnam). The protagonist is an impoverished French girl of about 15, whose family situation is complicated by neglect and abuse. Her mother is mentally unstable-'she'd suddenly be unable to wash us, dress us, or 
sometimes even feed us ... my mother experienced this deep despondency about life' (Duras 1984: 14) - and her elder brother's violence and opium addiction are enabled by her mother: 'she is still off in that other part of her life where blind preference takes her. Sealed off. Lost' (Duras 1992: 16). Her other brother, too, is vulnerable to the elder brother's ongoing violence: '[I wanted to...] save him from the living life of that elder brother superimposed on his own ... from the law which was decreed and represented by the elder brother, a human being, and yet which was an animal law ... filling ... the younger brother's life with fear' (Duras 1984: 7). These narrative details reveal that the girl is experiencing, even existing within, familial trauma before the narrative commences: 'I was afraid of myself, afraid of God. In the daylight I was less afraid, and death seemed less important. But it haunted me all the time. I wanted to kill - my elder brother ... to punish [my mother] for loving him so much, so badly ... to save my younger brother' (Duras 1984: 7).

Both novels commence with the girl's journey as she returns to boarding school. While crossing the Mekong River on a ferry, she meets a wealthy Chinese man who is at least ten years older than her. They begin a relationship that quickly becomes sexual. The girl's mother takes advantage of the situation and the Chinese man pays the elder brother's debts and passage to France. The narrative concludes when the girl also returns to France, thanks to the Chinese man's wealth.

The narrator in both tellings is markedly ambivalent and/or ambiguous about the girl's relationship with the Chinese man. She lets the reader consider whether the girl is traumatised by her family's duplicity, by the actual sexual relationship with the Chinese man, or by the colonial implications of their relationship. Thompson suggests 'the insidious trauma that haunts their relationship' is related to the girl's internal conflict between 'pure desire' and 'avarice', compounded by the Chinese man's humiliating conflict between his love for the 'white trash', his race and his wealth (2016: 9). Ince (2000) focuses on the colonial and racial: the girl's family's racism towards the Chinese man, the impossibility of their relationship, and the Chinese man's family's rejection of her (a subversion of colonial-racial relations). All these factors could create the traumatic affect of the work in shifting measures. I suggest it is also Duras's 
possible realisation that the character of the novels has less or even no agency, which makes these events traumatic.

This ambivalence and ambiguity arguably extend beyond narrative device. When The Lover was published, Duras indicated it was 'pure autobiography', but around six years later, she claimed it was 'an 'imaginative memory of time ... rendered into life' (Thompson 2016: 2). Her second telling, eight years after the first, was prompted by a falling out over the cinema adaptation of The Lover. Again, framed as autobiography in reaction to the film, The North China Lover covers the same events but with substantially different implications and nuances.

I suggest both tellings represent the experience of speaking the so-called unspeakable and demonstrate the affects of trauma. Exploring literary trauma theory and affect theory may explain Duras's impetus to tell her story twice.

The Unspeakability of Trauma

\footnotetext{
... I still can't understand however hard I try, [it] is still beyond my reach, hidden in the very depths of my flesh, blind as a newborn child. It's the area on whose brink the silence begins. What happens there is silence, the slow travail of my whole life. I'm still there, watching ... as far away from the mystery now as I was then (Duras 1984: 25)
}

In literary trauma theory, trauma is framed as 'a breach in the mind's experience of time, self and the world' that constitutes a wound (Caruth 1996: 3). For classical trauma theorists in this lineage, and particularly Caruth, trauma has been defined by its unspeakability (Balaev 2008: 151). Caruth asserts that "massive trauma precludes all representation because the ordinary mechanisms of consciousness and memory are temporarily destroyed ... the traumatic event [is] dissociated from normal mental processes of cognition ... and only returns belatedly' in the form of post-traumatic symptoms (Leys 2000: 266).

In the process of hearing spoken testimony of the Holocaust, Laub directly observed the unspeakable conundrum that survivors confront, describing it as:

an imperative to tell and thus come to know one's story ... Yet no amount of telling seems ever to do justice to this inner compulsion. There are 
never enough words, or the right words, there is never enough time, or the right time, and never enough listening or the right listening to articulate the story that cannot be fully captured in thought, memory and speech ... Yet the 'not telling' of the story serves as a perpetuation of its tyranny. The event becomes more and more distorted in their silent retention and pervasively to invade and contaminate the survivor's daily life (Felman and Laub 1992: 78, 79).

Other theorists, such as Mandel recognise that spoken trauma encompasses 'acute silences and epistemological gaps that reflect the impact of traumatic experience on the speaker's psyche' (Mandel 2006: 100). The unspeakable, for survivors, may be more objectively related to the limitations of language to convey the horror of trauma (or, one could say, the affect of trauma) than the capacity to relate the actual traumatic event. This small shift in emphasis, from a lack in the speaker to a lack in language itself, is significant.

Duras's repetition of her story and her lament about being unable to understand her traumatic family history without being led into a cycle of silence is a clear example of this compulsion. It is also pertinent that she did not agree with the way in which her 'testimony' in The Lover was being adapted into film (Ince 2000: 114). Is this evidence that her telling was inadequate, that the filmmaker, as a witness, was wanting, or that the filmmaker's telling was inadequate? Either way, this projects Duras back into a traumatic affect and leads to another telling, another striving to make meaning and be heard.

Literary trauma theory is moving away from understanding trauma as unrepresentable (Balaev 2014: 1). Stampfl contends that 'trauma' itself is the name of a realm of experience large and diverse enough to require a pluralistic conception of the unspeakable ... that recognises the trope's alternative or even antithetical possibilities' (2014: 16, 25). For Stampfl, the unspeakable should be considered a 'phase in the process of traumatisation' because 'traumatisation need not necessarily conclude in a state of involuntary, deeply conflicted silence' (2014: 16). This view fits with Laub's understanding of restoration through testimony and witness, and is consistent with clinical treatments of trauma. From this perspective, Duras's retellings may be described as a rebellion against traumatic silence: she is wrestling with her own psychic 
wound, trying to wrangle it into a form with which she can truly grapple, and perhaps escape, or at least have some relief from.

\section{Affects of Speech}

In considering the writing of Duras, and recognising her work as a 'confrontation with the silence of horror within the self and in the world', Kristeva articulates the question: 'how is the truth of pain to be spoken when the available rhetoric of literature and even of everyday speech always seems festive?' (1987: 140). She considers Duras's work to be 'stylistic[ally] awkward' and a 'discourse of blunted pain', with 'no distance, no escape ... no purification', 'leav[ing] writing just short of a complete distortion of meaning ... confin[ing] it to the laying bare of malady' (Kristeva 1987: 141). Kristeva's ultimate criticism of Duras, as I understand it, is that her narratives are noncathartic (1987: 141).

Truth telling among trauma survivors is what Caruth, relying on Freud, refers to as the 'crying wound' (1996: 8), and as Kristeva notes, Duras both expresses and inflicts pain as she pulls off the 'careful making up of [her]self', exposing this 'absolute vulnerability and melancholy' malady (Kluchin 2018: 43). The wound never heals because it can never be fully known (1996: 6). No witness, not even the victim, can return to the chronotope of wounding and make sense of it. They are always borne away from it by time, new experience, and by retraumatisation through lack of self-knowledge, the absence of empathetic witnessing, and the sheer segregation that trauma causes within the self and within relationships.

Is it for this reason that Duras, as a traumatised person and as a writer, never gives the reader the catharsis on which Kristeva appears to insist? Is it because Duras has never been set free of her crying wound? More importantly, would a cathartic telling be an existential sleight of hand, an insincere manoeuvre, for her as a traumatised person?

On a personal note, reading Duras as a survivor is comforting! It is even aesthetically preferable, because it is noncathartic. Trauma survivors know there is not a lancing, purging or cleansing of their wound. As a survivor, I don't 
want to experience post-traumatic symptoms, but I do experience them, because there is no cure for trauma: there is only an intermittent alleviation of symptoms. Catharsis in a narrative like Duras's would, for me, be like probing, or cutting into my trauma and making my wound deeper because I would not be able to accept it as truth or be able to willingly suspend my disbelief. Duras allows the reader to explore and observe the wound without judgment or expectation: to just be present with it and know that you also exist in that space.

But that is not the only reason why the cathectic bond with Duras is a source of comfort to me: it is also a comfort because when I witness her telling, she comes beside me in my own horror so that, in a way, and for a brief time, we share wounds (not like swapping war stories, but like two amputees may pre-empt and assist one another without verbal communication, because they know). Further, Duras indicates to me that perspectives shift with speaking. Duras reminds me that I am not trapped, that this here speaking may be inadequate, but there can be another speaking. Kristeva's work on Duras and her concerns about the noncathartic are vital, and I recognise that not every survivor will experience Duras as I have, but perhaps the cathectic aspect of Duras's oeuvre could be constructively explored.

As a psychoanalyst, Kristeva appears to focus, in her readings of Duras, on the necessity of self-knowledge, and the 'capacity to speak and act' for psychic transformation. She anecdotally found that her students (especially the 'fragile' ones) found themselves silent and seemingly 'imprisoned by the truth Duras reveals' (Kluchin 2018: 41, 42). In other words, the reader could be seen to ‘catch’ Duras's trauma.

Caruth asserts that trauma 'is never simply one's own' but implicates everyone (1996: 24). For her, listening to, and accepting testimony of the 'unrepresentable' [i.e. unspeakable], means being 'infected' by the trauma, and accepting an ethical obligation as a participant in the event of the trauma and the event of the telling (Leys 2000: 269). Caruth's articulation is that of a 'disease model', with trauma being described as contagious. This puts survivors, and writers, in a position where to speak is to harm, by spreading the trauma so that others are, so-to-speak, infected by it. 
I do not think that trauma is contagious as described by Caruth (categorising the clinical classifications of vicarious trauma is a different question). What is contagious is the affect of the traumatised person, and it is this shared affect that witnesses may experience.

Regarding affect, Tomkins asserts that: 'affects are ... responses that communicate and motivate at once both publicly outward to the other and backward and inward to the one who ... expresses his affects' (Tomkins 1966: vii). This non-lingual exchange builds shared affect. When reading a narrative, affective memories are engaged so that, by connecting the narrative with personal experience, an associated affect is triggered. Thus, the reader is affected, and may, in fact, acquire the writer's affect.

Anna Gibbs explains that affect is contagious and expressed mimetically (2010: 187). Affect contagion is 'the bioneurological means by which particular affects are transmitted from body to body' (Gibbs 2010: 191). The easy example of affect contagion is the smile response: it demonstrates how affect contagion produces a mimetic relationship between bodies (Gibbs 2008: 133)².

Kluchin indicates that Kristeva's students experienced fear or dread reading Duras because of textual/affective contagion. Then, instead of giving the reader a cathartic pivot, Duras gives them cathexis, 'an investment of psychic energy that cannot be discharged' (Kluchin 2018: 44). In Kristeva's view, this 'transmits' a symptom of the malady (which she describes as 'death') to the reader: silence which is 'not just any absence of speech ... it is the silence of the silenced, involuntary and utterly familiar ... militat[ing] against the production of speech' (Kluchin 2018: 47). This not only angers Kristeva, but to her it is unforgivable, because Duras does not assist the reader in 'putting oneself back together through the insight of recognising the truth ... it is not a recognition that sparks a passage toward wellness' (Kluchin 2018: 48).

Leaving a reader in discomfort, affected by truth, may be-I'd argue-preferable to the use of the unspeakable as a narrative device because the unspeakable disrupts identification. On encountering 'it was unspeakable', a reader tends to exit the narrative, disconnect empathy for the character, and activate their own 
worst fears (Stampfl 2014: 21). Alternatively, the reader may experience the unspeakable in a gratuitous way (Stampfl 2014: 17, 19, 20). As writers we may be fearful of causing harm by misappropriating or miscommunicating trauma, or be unable to trust readers' capacity for more than apathy, egocentrism or aberration, but I argue that using the unspeakable to escape these dilemmas carries a different risk: by avoiding these conversations perhaps we allow the unspeakable to exist unchallenged in both our writing, and our world. 3

Kristeva's reaction to Duras seems to come from her frustrated desire to restore and heal. She is making an ethical objection to the impact of the affect contagion of Duras's work on students she perceived as 'fragile' and 'oversensitive', who dreaded Duras 'especially when they felt weak' because of a symptom or truth that Duras 'creates' (Kristeva 1989: 227-228; Kluchin 2018: 42, 44). To Kristeva, Duras's 'disaster of words in the face of the unnameable affect', brings the reader to the 'verge of madness' (1989: 258).

As I read Kristeva for this paper, I also unwittingly became something like a petri dish. I identified with the students that Kristeva described as fragile/oversensitive and was projected into a classroom discussion of trauma. It could have been many classroom experiences layered together from memory: family law, paediatric nursing, high school English. I felt excruciatingly, microscopically, observable. Humiliation, terror, guilt, gripped my viscera and the physical experience of these affects overran me. The experience was nonlingual: it was unthinkable, in that my mind could not label it, but only perceive the physical symptoms. For a week, I was living with this heightened affect, and unconsciously, it made an appearance in the tone of this paper's draft.

While I hope not to become an experimental anecdote again, I am struck by the irony of being 'caught' and/or 'trapped' by Kristeva, given her critique of Duras. I am curious about the mimetic quality of the experience: did Kristeva's work merely trigger my pre-existing affect, or was Kristeva's own affect contagious?

Traumatised Agents

It is worth comparing specific details of Duras's tellings. There are small differences, such as the colour of the protagonist's shoes (gold in The Lover, 
black, bejewelled, scuffed in The North China Lover) and significant differences, such as the protagonist's anticolonial sentiments and the racial implications of her affair with the Chinese man. What is of further significance is what the narrative voice implies about the agency of the protagonist.

In The Lover, Duras writes in the first person: 'I'. She refers to the other characters as the Chinese man, my mother, my elder brother, and my younger brother. In contrast, Duras narrates The North China Lover in the third person. The protagonist is 'the girl' or 'the young girl' and 'the Chinese man' remains unnamed, as does 'the mother'. However, Duras names her brothers, Pierre and Paulo, and the houseboy, Thanh, a foundling her mother took in.

The naming of these characters provides is a barometer of perceived agency. In The Lover, Duras arguably believes she is a capable agent and projects her sense of power into the narrative. Her mother is infantilised by the description of her mental instability, with the protagonist asserting control over her: 'sometimes, those times I've mentioned, you can get anything you like out of her, she can't refuse us anything' (1984: 23), and realising her pre-held knowledge that 'their mother was a child. Their mother never knew pleasure' (1984: 39). The affair with the Chinese man occurs because 'she's doing what the mother would have chosen for her to do, if she'd dared, if she'd had the strength, if the pain of her thoughts hadn't been there every day, wearing her out' (1984: 25).

The fantasy of her control pervades the story. She seems to initiate and control the first sexual encounter: 'she wants to do it. And she does ... She touches him ... weeping, he makes love. At first, pain. And then the pain is possessed in its turn, changed, slowly drawn away, borne toward pleasure, clasped to it' (1984: 38). Despite this assertiveness, Duras soon writes that 'suddenly I have a pain. Very slight, almost imperceptible. It's my heartbeat, shifted into the fresh, keen wound he's made in me, he, the one who's talking to me, the one who also made the afternoon's pleasure' (1984: 48). This statement is characteristic of the ambiguities in the text. The pain seems more than physical, more than that caused by a loss of virginity. It is a wounding, but is it also love, tinged with the foresight of parting, or is it a traumatic wound caused by the Chinese man alone, 
or by the Chinese man in the context of the family trauma, and an emerging realisation that perhaps she is not the free agent she believed?

In any case, the family trauma dominates her relationship with the Chinese man. She determines to introduce him to her family, and we read that her brothers treat the Chinese man with contempt because he is Chinese and therefore assume that she does not and cannot love him (1984: 51). The presence of her elder brother is such that the Chinese man becomes nothing to her: 'my desire obeys my elder brother, rejects my lover' and thus she continues to glimpse small realities of her situation (1984: 52). Still, in the final reaches of The Lover, the protagonist has not accepted the revelation of her lack of agency, not even as the gossip about the relationship circulates, the Chinese man's family rejects her, and she begins to grasp that she has been reduced to white trash (1984: 88) and is as marginalised as the Chinese man (Medcalf 1992: 3). As the story concludes and she leaves for France, this reality has not broken through her denial, or her family's narrative of colonial superiority: she weeps secretly because she is not supposed to mourn a Chinese lover (1984: 111).

In The North China Lover there is no 'I', only 'the girl', or 'the young girl'. All the power has gone, and the girl has far less agency. It becomes much clearer that the girl has been 'groomed' by her mother and brother so that while her intent to profit from the Chinese man is, let's say, unconscious, she is privy, in a sense to her designated role in the family. As noted above, in The Lover she claims this role as if it empowers her and she is judgmental of her mother's vacillation. There, she does not see herself as an asset, an object, as her brother or mother see her. This misreading on her part infers grooming (the predatory conduct and psychological manipulation that prepares a victim for abuse). Her perspective has been deliberately distorted and manipulated prior to the encounter with the Chinese man by her family's situation and her 'role' in it.

When Duras describes the moments before the relationship becomes intimate in The North China Lover, the girl is naked on the bed 'in place, an offering' (1992: 67). The Chinese man's 'fear returns and he doesn't want her anymore' so she begins to take the initiative by undressing him, but she becomes fearful 
when he tells her there will be bleeding. She tries to get up: 'with his hands, he stops her from getting up. She doesn't try again. She would say she remembered the fear', and then her body 'has been breached, it is bleeding, its suffering is over. This can't be called pain anymore, it might be called death' (1992: 68-69). It is a potent (and then repeated) image of sacrifice: the girl's 'death' for the Chinese man's pleasure; her 'death' to pay for Pierre's debts and crimes, her mother's 'madness', for Paulo's vulnerability. In the eight years between writing, Duras has shifted from describing a romantic, consensual seduction of a willing virgin girl to something that resembles a rape where the victim has frozen with fear.

Accompanying the realisation that she has less agency than she might have believed is a depiction of the Chinese man that casts him as bigger, stronger and whiter than he was in the first book. An obvious question is whether the Chinese man was ever weak, hairless and effeminate, or if the difference pertains to factors in perception, and the changing cognition that comes with life experience, or whether Duras was trying to decrease the colonial and racial overtones of the relationship for the first novel (Ince 2000: 120). The relationship continues to be an ambiguous mix of love, abuse, business, and pleasure, but the girl is much more quickly cast as:

... his object, secretly prostituted to him alone. Nameless now. Offered up like a thing, a thing he alone has stolen. Taken, used, penetrated by him alone. Something suddenly unknown, a girl child without identity except that she belongs to him, is his sole estate - there is no word for that melded into him, absorbed in a totality that is itself just being born, called since the dawn of time by another, an unjust name: indignity (Duras 1992: 87).

It is not just the Chinese man's relationship with the girl that has changed. When he goes out with her family in this telling, he laughs off the racist and insulting behaviour and inserts himself into the social mix (1992: 145). Further, when Pierre, the indebted, opium addicted elder brother, laughs to see the girl and the Chinese man dancing, the Chinese man approaches Pierre and is able to scare Pierre by inferring he knows kung fu, and confronting Pierre with the truth that his laughter is false (1992: 151). 
It is much harder to accept the Chinese man and the girl's relationship as possibly being loving in The North China Lover, though the hints of this are also present. Possibly this is because Duras has had more than eight years since the first telling to re-evaluate. By telling her story differently Duras is demonstrating the impact that time, insight and self-knowledge can have on narrative inflection. For all writers, not only traumatised ones, the story we produce now will never be identical to the story we produce next, even if it covers the same matters and events. This is not because the events of the story have changed, but because the writer has changed. They have undergone an evolution of speech, among other evolutions.

It is hard not to wonder if it matters whether the relationship with the Chinese man was consensual (technically, it cannot have been because Duras was underage), whether there really was love, whether the girl was truly mercenary and he an opportunist. The truth seems to be that it was a complex melange but also that the Chinese man was a pivot point in her life that defies characterisation. For a time, he provided her with belonging and nurture. The abandonment she experienced at the end of their relationship marked her: 'I grew old at eighteen' (Duras 1984: 4). Yet in 1991 Duras wrote that 'writing [The North China Lover] made me deliriously happy. The novel kept me a year, enclosed me in that year of love between the Chinese man and the child' (1992: 1). If the reader can take anything redemptive from Duras, perhaps it is that late in her life, speaking about these events made her happy.

Conclusion

The unspeakable as a literary trope needs to evolve beyond a shorthand for events and experiences that are traumatic and off limits to representation. This does not mean that writers should be graphic or gratuitous about traumatic events. To do that is irresponsible and may minimise the gravity of trauma and/or harm readers. Evolving the unspeakable means drawing affected characters with a range of genuinely depicted and empathetically written posttraumatic symptoms. The trauma, after all, is not rigorously in the event: it is in the living after the event. 
In our creative practice, we may want to access our own psychological selfknowledge and the real lived experiences of survivors, not to appropriate stories or fictionalise survivors, but to fully realise what can be a nuanced and individual truth in every situation.

At least one quarter of the people in our society have experienced interpersonal trauma. To recognise and represent this in literature is an ethical obligation all writers must answer.

\section{Endnotes}

1. I am immensely grateful for the generous support of the peer reviewers, and I acknowledge that their influence and advice is present within this paper.

2. Physically and mentally, humans can only cope with a certain amount of fear, shame, terror or anger before entering a toxic state where the body cannot maintain its functions and the mind cannot sustain its processes of cognition. Panic is an example of this, occurring when fear-terror becomes so extreme that the modifying behaviour (freeze, fight, flight) becomes so selfdefeating and 'frenzied' that the subject's agency is compromised (Gibbs 2008: 131). This is fundamental to understanding what happens during a traumatic event. The consequence is, as Sedgwick and Frank have articulated, that:
the memory of the past experience of affect ... makes the individual slave to his own constructions ... One is either more or less afraid depending on the relationship between the memory of the past and the present construction, which either result in habituation or sensitisation or generalisation. But an individual who has felt terror once in connection with any object is well on the way to increasing this when his imagination transforms this experience as it is remembered (1995: 66).

This happens because each affective experience creates an internal narrative. Thus, when the affect is triggered again the associated past affect is reexperienced. Because of this, survivors re-experience horror, distress and fear when speaking about trauma, and witnesses may acquire horror, distress and fear. It is cyclic: speaking about trauma is traumatic and both traumatises and re-traumatises. Gibbs notes that fear is 'probably the most contagious of all affects' (2008: 131). Effective communication between survivor and witness can only occur when both parties to the exchange can manage their affect in a constructive way. 
3. I am reminded of The Great Derangement: climate change and the unthinkable by Amitav Ghosh which addresses the silence of literature regarding climate extremes. He suggests that the omission of extreme weathers representation in literature is a form of complicity that allows the perpetuation of climate denial. From my point of view, there is a parallel argument to be had regarding interpersonal trauma.

Works Cited List

American Psychiatric Association 2013 Diagnostic and statistical manual of mental disorders (5th ed) Arlington: American Psychiatric Association https://doi.org/10.1176/appi.books.9780890425596

Bakhtin, MM 1981 The Dialogic Imagination: four essays by MM Bakhtin, Michael Holquist (ed) Caryl Emerson and Michael Holquist (trans) Austin: University of Texas Press

Balaev, M 2008 'Trends in Literary Trauma Theory' Mosaic: An Interdisciplinary Critical Journal 41 (2), 149-166

Balaev, M 2014 'Literary Trauma Theory Reconsidered' in Michelle Balaev (ed) Contemporary Approaches in Literary Trauma Theory New York: Palgrave McMillan, 1-14

Caruth, C 1996 Unclaimed Experience: trauma, narrative and history Baltimore: John Hopkins University Press

Duras, M 1985 The Lover Barbara Bray (trans) New York: Pantheon Books (Random House)

Duras, M 1992 The North China Lover Leigh Hafrey (trans) New York: The New Press

Gibbs, A 2008 'Panic! Affect contagion, mimesis and suggestions' Cultural Studies Review 14 (2), 130-145

Gibbs, A 2010 'After Affect: Sympathy, Synchrony and Mimetic Communication' in Melissa Gregg and Gregory J. Seigworth (eds) The Affect Theory Reader Durham: Duke University Press

Herman, J 1992 Trauma and Recovery New York: Basic Books

Holquist, M 2002 Dialogism ( $2^{\text {nd }}$ ed) London: Routledge

Ince, K 2000 'Imaginary White Female: Myth, Race and Colour in Duras's L'amant de la Chine du Nord' in James S. William (ed) Revisioning Duras Liverpool: Liverpool University Press

Kluchin, A 2018 'Fragile Readers: textual contagion in Kristeva and Duras' philoSOPHIA 8 (2), 39-58

Kristeva, J 1987 'The Pain of Sorrow in the Modern World: the works of Marguerite Duras' Jensen KA (trans) PMLA 2 (2), 138-152 
Kristeva, J 1989 Black Sun: Depression and Melancholia Leon S. Roudiez (trans) New York: Columbia University Press

Leys, R 2000 Trauma: A Genealogy Chicago: University of Chicago Press

Mandel, N 2006 Against the Unspeakable: complicity, the Holocaust and slavery Charlottesville: University of Virginia Press

Medcalf, AC 1992 'Blurring the Boundaries? The sense of time and place in Marguerite Duras' L'Amant' Span: Journal of the South Pacific Assoc for Cwlth Lit and Language Studies No. 36 wwwmcc.murdoch.edu.au/readingroom/litserv/DPAN/36/Medcalf.ht $\mathrm{ml}$

Sedgwick, EK and Frank, A 1995 'Shame in the Cybernetic Fold: Reading Silvan Tomkins' Critical Enquiry 21 (2), 496-522

Sedgwick, EK and Frank, A 1995 Shame and Its Sisters: a Silvan Tomkins Reader Durham and London: Duke University Press

Stampfl, B 2014 'Parsing the Unspeakable in the Context of Trauma' in Michelle Balaev (ed) Contemporary Approaches in Literary Trauma Theory New York: Palgrave McMillan, 15-41

Thompson, ZB 2016 'Beyond Symbolic Rape: the insidious trauma of conquest in Marguerite Duras's The Lover and Eileen Chang's 'Lust, Caution” Feminist Formations 28 (3), 1-26 